\title{
PELATIHAN PEMBUATAN MEDIA PEMBELAJARAN MULTIMEDIA MENGGUNAKAN APLIKASI LECTORA INSPIRE YANG DIINTEGRASIKAN DENGAN CAMTASIA STUDIO BAGI GURU SD DI PESISIR TELUK TOMINI
}

\author{
Daud Yusuf ${ }^{1)}$, Rusiyah²), Sri Maryati ${ }^{3)}$ \\ 1)AProgram Studi Pendidikan Geografi, Universitas Negeri Gorontalo, Kota Gorontalo, Gorontalo \\ Corresponding author : Daud Yusuf \\ E-mail : daud@ung.ac.id \\ Diterima ..... 20XX, Disetujui ..... 20XX (10 pt)
}

\begin{abstract}
ABSTRAK
Pelatihan Pembuatan Media Pembelajaran Multimedia Menggunakan Aplikasi Lectora Inspire Yang Diintegrasikan dengan Camtasia Studio bagi Guru SD Di Pesisir Teluk Tomini. Kegiatan pengabdian masyarakat dilaksanakan di Kecamatan Kabila Bone dengan sasaran adalah Guru Sekolah Dasar. Kegiatan ini akan melatih guru-guru untuk membuat media pembelajaran multimedia menggunakan aplikasi Lectora Inspire yang dintegrasikan dengan Camtasia Studio. Video pembelajaran yang dihasilkan menggunakan gambar, suara, video dan animasi yang dikemas menjadi materi pelajaran yang interaktif. Hasil dari video ini bisa diunggah di media sosial seperti Youtube, Instagram, dan Facebook sehingga mudah untuk dimanfaatkan oleh murid.
\end{abstract}

Kata kunci: Lectora Inspire, Camtasia Studio, Multimedia, Kabila Bone

\section{ABSTRACT}

Training on Making Multimedia Learning Media Using the application Lectora Inspire Integrated with Camtasia Studio for Elementary School Teachers in Tomini Bay Coast. Community service activities are carried out in Kabila Bone District with the target being Elementary School Teachers. This activity will train teachers to create multimedia learning media using the application Lectora Inspire which is integrated with Camtasia Studio. The resulting learning videos use images, sounds, videos, and animations that are packaged into the interactive subject matter. The results of this video can be uploaded on social media such as Youtube, Instagram, and Facebook so that it is easy for students to use.

Keywords: Lectora inspire, Camtasia Studio, Multimedia and Kabila Bone

PENDAHULUAN

Pandemi Covid 19 yang belum usai,
memberikan dampak yang cukup nyata 
khususnya di dunia pendidikan. Para pendidik dituntut untuk berkreasi dalam membuat media pembelajaran yang dapat diserap dan dipelajari oleh siswa secara muda melalui media secara online.

Berbagai aplikasi yang ada telah disajikan dan ditawarkan ke publik pendidikan baik itu yang sifatnya berbayar atau gratis sekalipun. Beberapa aplikasi ini memberikan beberapa keunggulan dan kemudahan sehingga para pendidik dapat secara mudah memanfaatkanya. Pemanfaatan aplikasi untuk membuat media pembelajaran sudah diberikan secara kolektif oleh dinas pendidikan, namun masih ada kendala dari beberapa guru yang belum secara optimal memahami dan mampu membuat media interaktif.

Kecamatan Kabila Bone Kabupaten Bone Bolango yang berada di Pesisir Teluk Tomini memiliki 11 Sekolah Dasar Negeri yang tentunya memerlukan pelatihan dalam membuat Video Pembelajaran Interaktif. Para guru yang ada di sekolah ini diharapkan mampu secara mandiri membuat media pembelajaran.

Lectora Inspire adalah salah satu aplikasi pembuat video pembelajaran yang menarik dan mudah digunakan. Dengan mengintegrasikan dengan Camtasia Studio maka tampilan Video Pembelajaran lebih interaktif bagi murid dan siswa yang belajar.

Berdasarkan fakta dan pentingnya bagi Guru Sekolah Dasar skill dan kemampuan dasar dalam membuat media maka perlu dilakukan kegiatan pengabdian masyarakat dengan tema "Pelatihan Pembuatan Media Pembelajaran Multimedia Menggunakan Aplikasi Lectora Inspire Yang Diintegrasikan dengan Camtasia Studio bagi Guru SD di Pesisir Teluk Tomini “. Rumusan masalah dalam kegiatan ini adalah bagaimana membuat media pembelajaran menggunakan aplikasi Lectora Inspire dan Camtasia Studio ?. Solusi yang ditawarkan kepada Pemerintah Kabupaten Bone Bolango adalah memberikan pelatihan pembuatan media pembelajatan multimedia bagi Guru Sekolah Dasar di Kecamatan Kabila Bone Kabupaten Bone Bolango.

Dengan memberikan pelatihan kepada guru sekolah dasar di Kecamatan Kabila Bone maka diharapkan:Mempunyai keterampilan membuat media pembelajaran interaktif, Mempunyai keterampilan mengunggah video pembelajaran di Youtube, Mempunyai keterampilan membuat video dari gambar-gambar di sekitar sekolah.

\section{METODE}

Tahapan persiapan dilakukan dengan tahapan berikut; Melakukan komunikasi dengan mitra dalam hal ini Pemerintah Kecamatan Kabila Bone. Melakukan pendataan peserta kegiatan dan lokasi kegiatan. Observasi lokasi kegiatan dalam situasi pandemi dengan menerapkan protocol Kesehatan. Kegiatan ini dilaksanakan dengan tahapan berikut :

Penjelasan tentang aplikasi Lectore Inspire dan Camtasia Studio mengenai fungsi yang dapat dilakukan dengan aplikasi tersebut. Instalasi aplikasi Lectore Inspire dan Camtasia Studio. Pembuatan Video Pembelajaran. Perekaman hasil menggunakan camtasia studio. Extrack hasil. Download. Pembuatan akun youtube. Publish pada media sosial youtube. Program ini akan dilanjutkan dengan pelatihan pembuatan video animasi menggunakan aplikasi Proshow dan Flash. 


\section{HASIL DAN PEMBAHASAN}

\section{HASIL}

Langkah-langkah pembuatan video

pembelajaran menggunakan aplikasi lectora inspire :

1. Instalasi aplikasi lectora inspire

2. Instalasi camtasia studio

3. Membuka aplikasi lectora inspire dengan tampilan awal sebagai berikut :

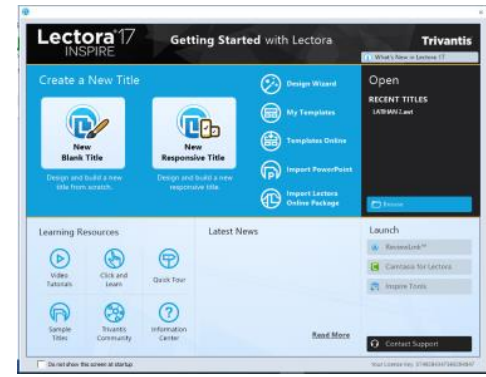

Gambar 1. Kotak Dialog ketika pertama kali membuka Lectora Inspire

4. Pilih new blank untuk memulai pembuatan video.

\section{Add Text}

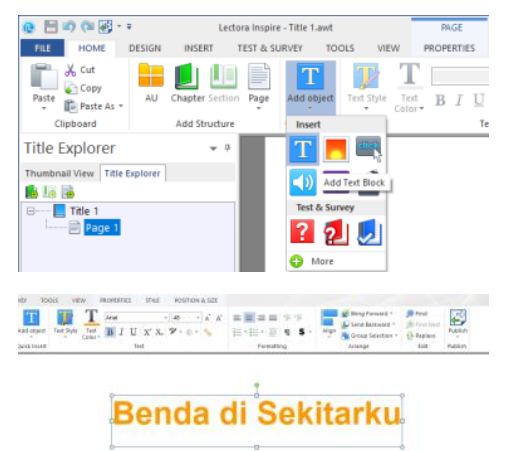

Gambar 2. Tampilan add text

6. Add Image seperti pada gambar berikut ini :
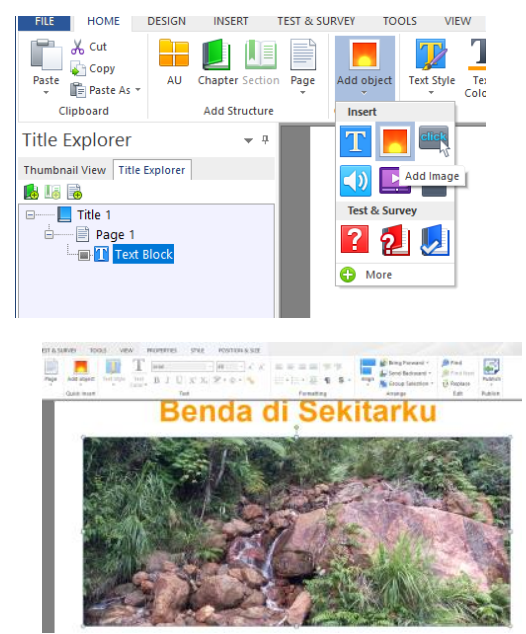

Gambar 3. Tampilan Add Image

7. Add Video seperti pada gambar berikut ini :
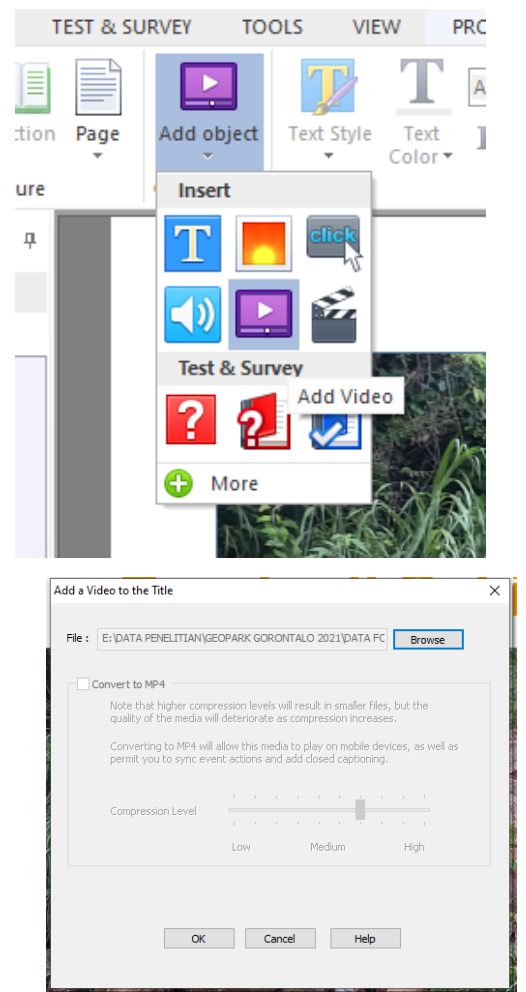

Gambar 4. Tampilan Add Video (a)

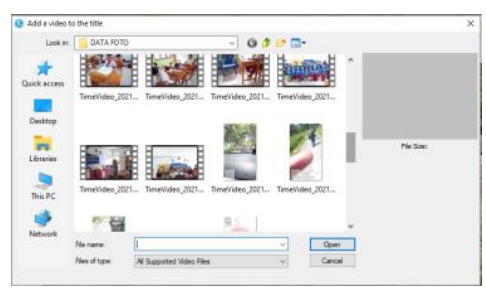

Gambar 5. Tampilan Add Video (b)

8. Add Button (tombol) 


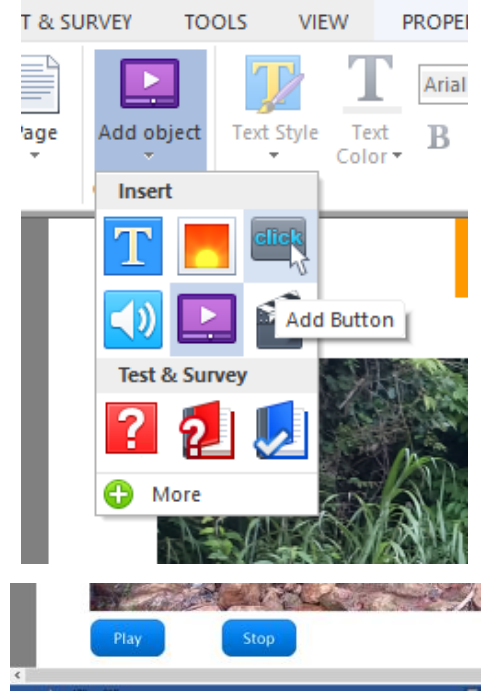

Gambar 6. Tampilan Add Button

9. Save Project seperti pada gambar berikut ini :
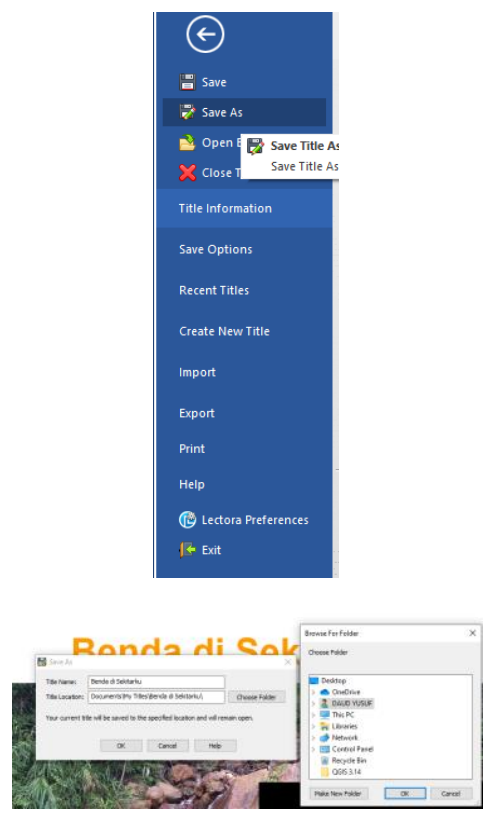

Gambar 7. Tampilan Save As

10. Pilih menu Publish seperti pada gambar berikut ini :

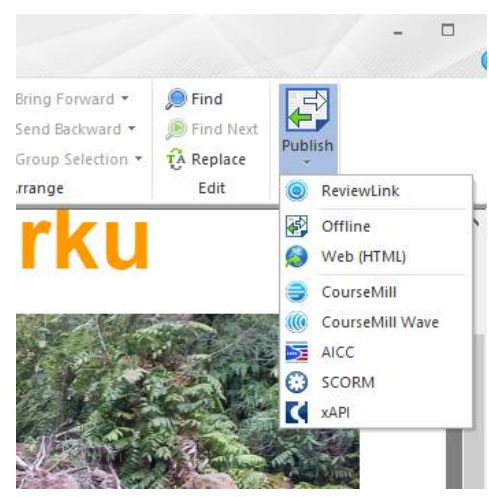

(a)

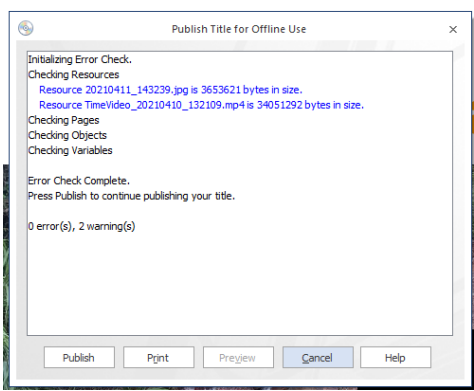

(b)

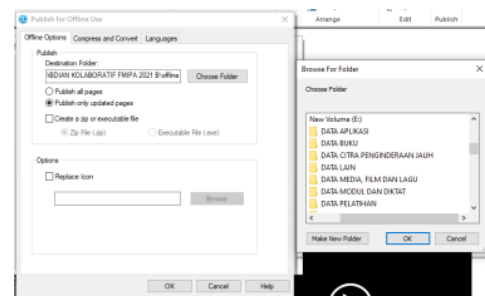

( c)

Gambar 8. Tampilan Publish (a,b,c) 11. Buka hasil Publish seperti gambar berikut :

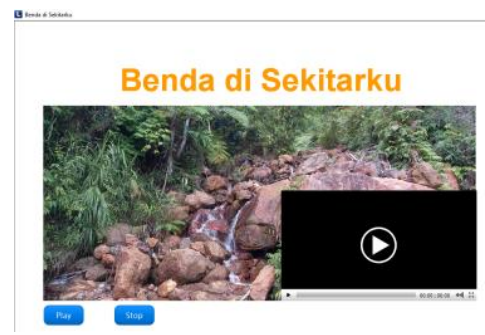

Gambar 9. Hasil Video Pembelajaran 12. Buka aplikasi Camtasia Studio seperti pada gambar berikut :

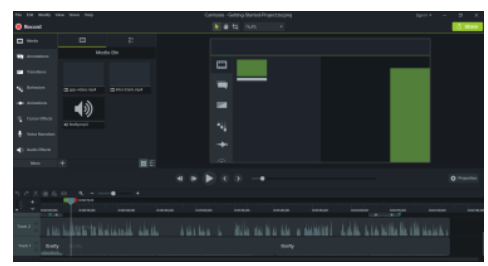

Gamba 10. Tampilan Awal Camtasia Studio 


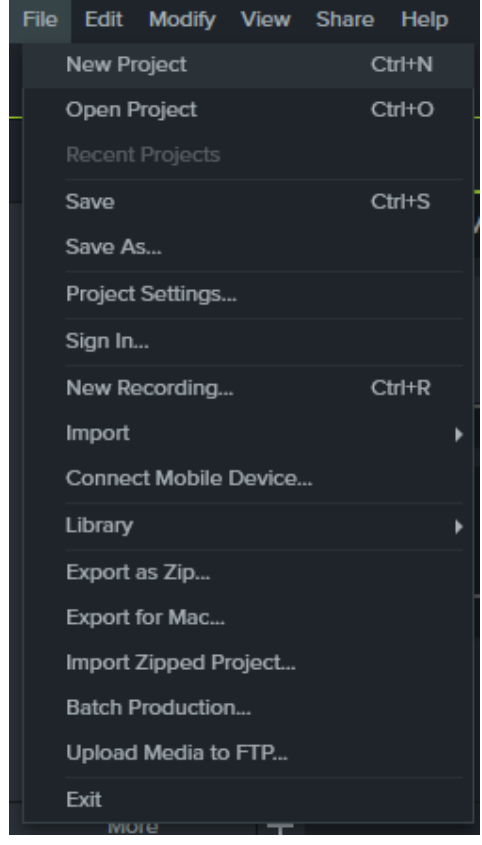

Gambar 11. New Project

13. Import video seperti gambar berikut :

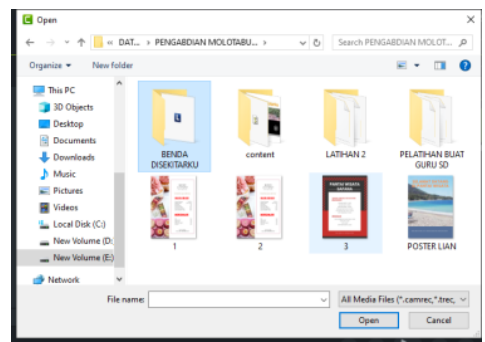

Gambar 12. Tampilan Import Video

14. Edit untuk menambah keindahan tampilan video :

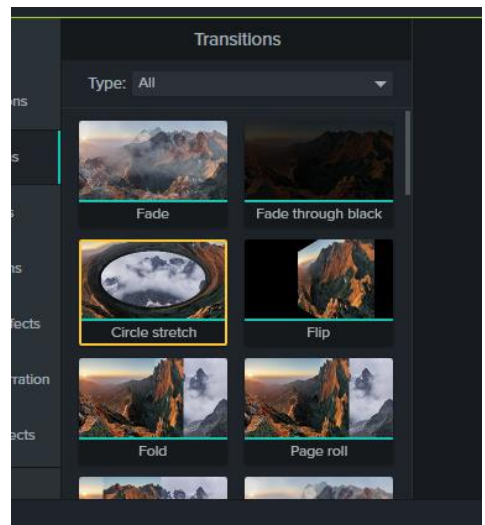

Gambar 13. Tampilan Edit Transision

15. Pilih share untuk membuat hasil akhir

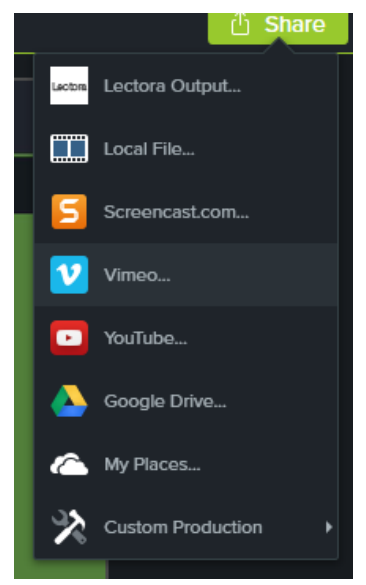

Gambar 14 Tampilan Share

16. Video selesai.

\section{Pembahasan}

Lectora Inspire merupakan aplikasi yang dapat digunakan untuk membuat berbagai macam media pembelajaran dalam berbagai bentuk. Hasil dari Lectora Inspire diintegrasikan dengan Camtasia Studio sehingga video pembelajaran dapat disimpan atau dipublikasi ke youtube. Beberapa media yang dapat dibuat menggunakan lectora inspire adalah quiz, games dan materi pembelajaran.

\section{SIMPULAN DAN SARAN}

Lectora Inspire adalah aplikasi pembuat video pembelajaran dengan berbagai macam keunggulan fitur dan kemudahan dalam pembuatannya. Aplikasi ini telah diintergrasikan dengan camtasia studi sehingga hasilnya dapat secara langsung dipublikasika melalui aplikasi youtube atau disimpan di drive penyimpanan.

Lectora Inspire dikembangkan oleh pihak sekolah untuk memberikan pengetahuan dalam mendesain media pembelajaran dan media lain yang menunjang pendidikan bagi guru sekolah dasar sehingga meningkatkan kualitas 
pembelajaran di sekolah.

\section{DAFTAR RUJUKAN}

https://lectora-inspire.software.informer.com

https://camtasia-studio.com

Yemima Otoluwa Pengembangan Media

Pembelajaran Berbasis Lectora

Inspire Yang Diintegrasikan Dengan

Camtasia Studio Pada Mata

Pelajaran Geografi Materi Sistem

Informasi Geografi. Vol 1, No 1 (2020):

Jambura Geo Education Journal

(JGEJ) - Articles

Trisna Ulfatuzzahra Development of learning media based on Lectora Inspire on social science subjects http://journal.uny.ac.id/index.php/hsip i

Daud Yusuf. Tutorial Pembuatan Video Pembelajaran Menggunakan

Camtasia Studio. 2017 